\title{
Governance of large-scale environmental problems - the case of climate change
}

\author{
Qie Sun* \\ Department of Industrial Ecology \\ Royal Institute of Technology (KTH) \\ Teknikringen 34 \\ SE-10044, Stockholm, Sweden \\ E-mail: qie@kth.se \\ *Corresponding author

\section{Ronald Wennersten} \\ Professor of the Department of Industrial Ecology \\ Royal Institute of Technology (KTH) \\ Teknikringen 34 \\ SE-10044, Stockholm, Sweden \\ E-mail: rw@kth.se
}

\author{
Nils Brandt \\ Associate Professor of the Department of Industrial Ecology \\ Royal Institute of Technology (KTH) \\ Teknikringen 34 \\ SE-10044, Stockholm, Sweden \\ E-mail: nilsb@kth.se
}

\begin{abstract}
This paper focuses on the management of climate change mitigation (CCM), seeking a working institution capable of addressing its cross-scale and multi-level challenges. Currently, two most studied forms of institution are co-management and transnational networks, of which a common point is that they both attempt to build up cooperative networks. While cooperative networks have a general form of viability, this paper develops an interactions check table (ICT) to illustrate those interactions between stakeholders in those two forms of cooperative networks. On the basis of the ICT analysis, this paper makes suggestions for improving cooperative networks as a working institution.
\end{abstract}

Keywords: climate change mitigation (CCM); co-management; transnational networks; cooperative networks.

Biographical notes: Qie Sun is a PhD student at the Department of Industrial Ecology, Royal Institute of Technology, Sweden. He received his Master of Management (2006) degree from the Ocean University of China, Qingdao, China. His research focuses on the management and assessment of climate change mitigation projects, especially as regard the clean development mechanism and Chinese energy and mitigation policies. His research interests also include environmental economics, sustainable urban planning and decision-making techniques.

Ronald Wennersten is the professor and the head of the Department of Industrial Ecology, Royal Institute of Technology (KTH), Sweden, the head of the Joint Research Centre for Industrial Ecology, Shandong University, China, and a guest professor at the Shandong University and the South East University, China. He has published over 100 books and articles in international journals and conferences. He is an active member of various international scientific organisations and serves as an editorial board member of various prestigious international journals.

Nils Brandt is an associate professor of the Department of Industrial Ecology, Royal Institute of Technology (KTH), Sweden. He has published more than 70 books and articles in international journals and conferences. He has supervised/co- supervised many $\mathrm{PhD}$ and master students. His research area includes sustainable urban planning, industrial ecology, climate change actions and strategies, environmental system analysis and ecological engineering.

\section{Introduction}

There is widespread consensus that mitigation is a necessary option to avoid long-term irreversible climatic change and its likely devastating consequences (Houghton, 2001; IPCC, 2007). In practice, an increasing number of efforts have been made to mitigate climate change, for instance emissions trading, joint implementation and clean development mechanism (CDM) as proposed by the Kyoto Protocol, the ICLEI's (International Council for Local Environmental Initiatives) Cities for Climate Protection (CCP) campaign, and a good many voluntary local CCM projects. Effective CCM calls for broad participation of stakeholders, their active contributions and more importantly, a working institution for managing stakeholders and actions (Dietz et al., 2003; Gustavsson et al., 2006; Sun et al., 2007).

Since Hardin's (1968) seminal paper, studies have been using the 'commons' perspective to look at a variety of resources and environmental problems. Common resources (or commons for short) refer to natural resource or environment systems open to all. 
Since the 1990s, large-scale environmental problems, e.g. climate change, have been incorporated into the scope of common problems, which originally concentrated on small-scale common-pool resources (CPRs) (Dietz et al., 2003; Feeny et al., 1990; Kennedy, 2003; Ostrom, 1990; Ostrom et al., 1999; Paavola, 2008; van Laerhoven and Ostrom, 2007). A CPR is a natural or manmade resource system that is sufficiently large to make it costly (but not impossible) to exclude potential beneficiaries from obtaining benefits from it (Ostrom, 1990). In this paper, commons and CPRs are both used to indicate resource or environment systems, without referring to any property arrangements. On the basis of a large number of theoretical studies and empirical evidence, many common resource systems have proven of enduring and developing under effective governance institution (Agrawal, 2002; Dietz et al., 2003; Ostrom, 1990; Ostrom et al., 1999; Stern et al., 2002). Even for large-scale environmental problems, sustainability is viable when a working institution is established, e.g. the international treaty regime to reduce the anthropogenic impact on the stratospheric ozone has been widely considered to be a successful effort to protect the global atmosphere (Barrett, 1990; Dietz et al., 2003). However, such success has not been universally achieved in handling other largescale environmental problems. For example, the case of CCM has frequently been identified as a 'problem of tragedy' (Kennedy, 2003; Milinski et al., 2006; Stern et al., 2002).

Large-scale environmental problems usually span time, geographical space and administrative jurisdictions, and synthesise ecological, social and economic challenges. Therefore any approach to handling these problems needs to understand their crossscale nature and meet the multi-level challenges involved (Berkes, 2006; Cash et al., 2006). It must be pointed out that 'scale' in this paper has two meanings: one refers to the spatial extension of a resource system, e.g. small- and large-scale commons, while the other is the administrative scale, the levels of which encompass various points along the jurisdictional dimension: international, national, local (municipal), community (organisation and civil society) and private (commercial, household and individual). An increasing amount of evidence suggests that a traditional 'top-down' centralised governance system is less suitable for such challenges, and that management of large-scale commons requires the creation and implementation of a more robust governance institution by which cross-scale and multi-level challenges can be addressed (Carlsson and Sandström, 2008). Existing studies on governing climate change have attempted to achieve this mainly in two ways: co-management (or cross-level interplay) which aims to incorporate different actors on different administrative levels, typically national government and resource users (Adger et al., 2005; Berkes, 2006; Carlsson and Berkes, 2005; Carlsson and Sandström, 2008; Young, 2006), and transnational networks in which local actions are centrally focused (Betsill and Bulkeley, 2004; 2006).

\section{$2 \quad$ Main Considerations}

This paper adopts a theoretical approach of the commons and seeks to improve the governance of the large-scale environmental problem, climate change. Effective management of a large-scale common problem requires a deep understanding of its intrinsic nature. Thus, this paper first revisits the characteristics of climate change, which serve as the theoretical basis for studying the large-scale common problem. Next, the paper focuses on the institution for managing CCM. Specifically, the two most studied forms of institution, co-management and transnational networks, are reviewed with respect to their effectiveness in terms of governing the large-scale common problem of climate change. The paper then attempts to identify a general form of institution, namely co-management, which might be able to address the cross-scale and multi-level challenges of CCM. ICTs are developed to illustrate the theoretical characteristics of types of interactions between various stakeholders in the two forms of institution and on the basis of the ICT analysis the paper makes suggestions on improving the management of current institution with the aim of sustainable governance of climate change. Finally, the paper concludes with a short summary.

\section{Characteristics of Climate Change}

This section discusses the main characteristics of climate change, including: (1) climate change as a large-scale common problem, (2) physical characteristics of climate change, and (3) property rights for governing climate change.

\subsection{Climate change as a large-scale common problem}

Early work on commons focused heavily on local and regional CPRs, for instance pasture land, drainage systems and fisheries (Dietz et al., 2002; Feeny et al., 1990; Ostrom, 1990). In the past decade, studies of commons have enlarged their scope and have started to look at large-scale resource and environment systems, such as biodiversity, climate change and other ecosystem services. While principles generated from local and regional CPRs are necessary and enlightening, they are inadequate when applied to global environmental problems (Adger et al., 2005; Berkes, 2006; Dietz et al., 2003; Ostrom et al., 1999). The difficulties include scaling-up problems and the problem of distinguishing between environmental pollution and resource management.

A clear difference between small- and large-scale commons is the so-called scaling-up problem, i.e. the extent of a resource system and the number of actors using or having impacts on the system. A large-scale resource system usually involves large numbers of actors, who are usually much more heterogeneous (Dietz et al., 2002). This creates a rather complex situation, in which agreement on rules and their enforcement are very difficult. Other problems associated with the scaling-up problem include strong historical dependency, broad social settings, large cultural diversity, accelerating dynamics, and huge economic incentives and dependencies (Ostrom et al., 1999). Intertangled with many or all of these problems, global environmental problems are regarded as one of the most important challenges that require governance from international cooperation to local contributions (Dietz et al., 2003).

The other problem is that of distinguishing between environmental pollution and resource management. The differentiation between stock-flow and fund-service resources is especially illuminating in understanding this distinction. CPRs usually belong 
to the category of stock-flow resources, i.e. resources materially transformed into what they produce (Daly and Farley, 2003; Ostrom, 1990). If the appropriation rate keeps exceeding the sustainable yield of the stock, the resource will shrink and even become extinct in the end. Sustainable management of CPRs seeks to balance provision of the stock against the appropriation rate. In contrast, managing environmental problems involves two objects, i.e. a pollutant and an environmental sink of absorption. The environmental sink, as defined in Daly and Farley (2003), is typically a fund-service resource that provides the capacity of absorbing the pollutant at a fixed rate, rather than becoming part of a product. The overall aim thus becomes restraining the amount of pollutants within the absorption capacity of the environmental sink. However, the capacity is difficult to determine in most cases. People would not stop 'benefiting' from emitting pollutants into the atmosphere until they noticed the capacity as being seriously deteriorated. In the case of climate change, people emit greenhouse gases (GHG) into the atmosphere without considering the externalities induced by the emissions. It has taken quite a long time for people to realise the externalities, still with many uncertainties. Managing CCM entails reductions in GHG emissions, which requires information about anthropogenic GHG emissions and their impacts in relation to the absorption capacity of the atmospheric sink. Additional costs, often very large, are needed to mitigate GHG emissions and this is a significant barrier to implementation of practical CCM actions.

\subsection{Physical characteristics of climate change}

Two major physical characteristics of commons are excludability and rivalry (Berkes, 2006; Daly and Farley, 2003; Dietz et al., 2002; Feeny et al., 1990). Excludability means the arrangement of excluding people from using the resource other than the owners of a defined group. In some cases, the exclusive arrangement of a resource, especially one such as a large-scale environmental sink, might be too costly to achieve in practice, although it is theoretically possible. Rivalry (or subtractability, non-jointness) relates to the natural attribute of a resource, with which the consumption of one unit by one person precludes the unit from being consumed by the other. Rivalry refers not only to quantitative rivalry but also to qualitative, e.g. if a ton of waste water is disposed of in a lake, there is less capacity for the lake to process another ton of waste. Note that both excludability and rivalry are characteristics that vary in degree rather than being all or nothing (Ostrom and Ostrom, 1977). Some studies, e.g. Daly and Farley (2003), exclude qualitative rivalry resources, such as the atmospheric sink, from the rivalry category.

As discussed above, two objects should be considered in the case of CCM, namely GHG emissions and the atmospheric sink. GHG are a pure externality of anthropogenic activities in terms of climate change, and are non-rival, non-excludable and undesirable (Daly and Farley, 2003). Non-rivalry means that the impacts caused by GHG emissions affect many people at the same time. Non-excludability describes the original arrangement that nobody is excluded from the right of emitting GHG and paying nothing. Therefore, significant problems of overemission are very likely to occur before excludable rules are established, especially when the costs of reducing GHG are large. Since GHG is an undesirable environmental 'bad', a theoretical option is to internalise the externalities of GHG into the costs of energy consumption, e.g. levying carbon tax on fossil fuels or subsidising low-carbon fuels. However, such excludable rules have only covered a corner of the arena to date, and effective rules have not been available in most fields of daily production and living. As mentioned above, the atmospheric sink represents qualitative rivalry and deterioration is not easily observed until the threshold. The atmospheric sink is also a non-excludable resource since either the harms of climate change or the benefits of atmospheric improvements cannot be divided and allocated to a specific group of people. However, this gives rise to another challenge of CCM, namely the free-riding problem - where everyone waits to benefit from reductions made by others, while everyone harms others by his/her emissions (Dietz et al., 2002). We therefore argue that effective management of climate change should contain strategies on reducing GHG and on protecting the atmospheric sink.

\subsection{Property rights for governing climate change}

A property regime under which a resource is held is an important part of institutional design. Categories of property regimes, i.e. who controls the access to a certain resource system, include: private property, government property, collective property and open access (i.e. no-one's property) (Dietz et al., 2002; Feeny et al., 1990; Ostrom et al., 1999; Stern et al., 2002). Among these four forms of property rights, an open access system almost always leads to extinction of a resource that is in great demand. Both successes and failures, however, have been recorded in the other three types of property rights, and no single category has proven best for governing various types of commons (Stern et al., 2002).

Regarding climate change, the atmospheric sink is intrinsically difficult to divide and it is thus impossible for some users to be excluded from the whole. The discussion about property rights mainly focuses on the definition and distribution of emission rights. Given that collective property could be broadly defined so as to cover government property, climate governance regulations constituted by national climate policies and international conventions can be understood as forms of collective property to restrain GHG emissions (Paavola, 2008). The right of some users to release GHG emissions, the amount they are allowed to release and the cost charged for these emissions are necessary constituents defining collective property in one way or another. Meanwhile, emission rights transferred into tradable goods are governed under private property. For example, in a CDM project, the amount of GHG reduction accredited to a developing country can be sold to an industrialised country for compliance with the Kyoto Protocol commitment of the latter. This arrangement provides large flexibility for reducing GHG emissions in a cost-effective way (IPCC, 2007). Although the property regimes under which the emission rights are defined are important, this information has not been sufficient to draw robust conclusions on sustainable institution for managing CCM (Feeny et al., 1990; Stern et al., 2002). 


\section{Institution for Governing Climate Change}

Governance of commons usually resorts to studies of developing and implementing institution. Institutional design for smallscale CPRs has mainly focused on working principles that encourage collective actions among resource users, while studies of governing large-scale commons have concentrated on how to address the cross-scale and multi-level challenges through various forms of institution (Agrawal, 2002; Betsill and Bulkeley, 2007; Dietz et al., 2002; Ostrom, 1990; Paavola, 2008). Berkes (2008) suggests that this could be done at various levels of institution that interact horizontally (across the same level) and vertically (across various levels). Within a diversity of forms of institution, the interests of existing studies have mainly fallen into two categories: co-management (or cross-level interplay), which is intended to incorporate different actors vertically across various administrative levels (Adger et al., 2005; Berkes, 2006; Carlsson and Berkes, 2005; Carlsson and Sandström, 2008; Young, 2006), and transnational networks, in which local actions horizontally across national boundaries are the central focus (Betsill and Bulkeley, 2004; 2006). In the rest of this section, we review the two forms of institution and respectively refer them to CDM projects and the ICLEI CCP campaign.

\subsection{Co-management}

Co-management is the most broadly discussed form of institution to date for addressing the multi-level challenges of commons. The idea of co-management is to overcome the weakness of the traditional 'top-down' system of resource management and is founded on the basis of power- and responsibility-sharing between governments and local communities (Berkes, 2006; Carlsson and Sandström, 2008; Cash et al., 2006; World Bank, 1999). Carlsson and Berkes (2005) summarise the characteristics of comanagement as being: (1) explicitly associated with natural resources management; (2) regarded as a kind of partnership between public and private actors; and (3) not a fixed state but a process that takes place along a continuum. Given that the administrative scale of governance encompasses international, national, municipal, local community and private level, co-management amounts to collective actions among stakeholders spanning these levels (Figure 1). Founded on vertical cross-level governance, comanagement aims to change the traditional top-down system into a flat social network and re-configure the power and responsibility among stakeholders (Carlsson and Sandström, 2008; Cash et al., 2006; World Bank, 1999). All stakeholders using the resource or having impacts on it, no matter to which level they belong, should take part in the co-management and cooperate with each other. In order to unravel the essence of co-management, many studies turn to investigating the relationship between a national government, or a state, and a community of local resource users. Interactions between a government and resource users may create four alternative images, namely exchange system, overlapping sectors, state-nested system and community-nested system (Carlsson and Berkes, 2005). However, if the multiple roles played by the government and the variety of actions taken by the community are considered, the relationship should be elucidated within an image of network and co-management can hence be understood as a structure of cooperative network (Carlsson and Sandström, 2008). Co-management, constituted by different stakeholders and/or with different power and responsibility arrangements, can be expressed in several other forms of institution, e.g. issue networks, policy community, polycentric systems and boundary organisations (Berkes, 2006; Carlsson and Berkes, 2005). In addition, note that co-management is not a single type of interplay vertically across levels of governance, although it might be a promising format under which management can be improved. Some other types of cross-level interplay, together with respective driving forces and appearance patterns, are described by Young (2006).

Although the discussion about co-management has generally concentrated on climate change, we argue that many CCM projects with multi-level partners can be regarded as practical exercises in co-management. Worldwide, CDM is a popular type of CCM project, and can be referred to as an example of co-management. Comparisons between CDM projects and the theory of comanagement can assist in (1) gathering empirical evidence to test and improve the theory of co-management, and (2) applying the knowledge of co-management to better management of CCM projects. The CDM allows GHG reduction (or removal) projects in developing countries to earn certified emission reduction (CER) credits, which can be sold to industrialised countries to meet a part of their reduction targets under the Kyoto Protocol. Worldwide, CDM has gained much interest, since it not only helps industrialised countries reduce their GHG emissions in a cost-effective way, but also aims to promote sustainable development in host countries (Olsen and Fenhann, 2008; Sutter and Parreño, 2007). Since the beginning of 2006, the mechanism has already registered more than 1,500 projects and is anticipated to produce more than 1.5 billion CERs by 2012 , the end of the first commitment period (UNFCCC, 2009a).

Generally, a CDM project can be visualised as shown in Figure 2, where two partners participate, i.e. a project owner from a developing country and an investor from an industrialised country. In order to be registered as CDM, the project must first be approved by relevant designated national authorities (DNA), validated by a designated operational entity (DoE), and then approved by the CDM executive board (EB). After the project is registered, the practical amount of GHG reduction is monitored by the project owner (or other parties if needed) within a crediting period. This has to be verified by another DoE, and the verified CER can then be credited to the industrialised country's account. As illustrated in Figure 2, participants in a CDM project include international organisations, national authorities, a project owner, investors and third party DoEs, spread over public and private sectors and over multiple administration levels. Every participant fulfils its own responsibility and cooperates with the others as defined under the CDM framework. The interactions between participants occur in a flat network which is established on the basis of power and responsibility reconfiguration, rather than the traditional top-down hierarchical system. Therefore, the procedure for CDM projects, i.e. from reconfiguring participants' power and responsibility, negotiating regulations and requirements, carrying out project actions, to monitoring, verifying and approving the amount of CER, can be understood as the dynamics of co-management. 


\subsection{Transnational networks}

An alternative to addressing the multi-level complexity is to focus on horizontal governance structures of large-scale commons, the so-called transnational networks (Berkes, 2008; Bulkeley, 2005). By definition, a transnational network involves a number of actors operating simultaneously or cooperating across national boundaries (Betsill and Bulkeley, 2004; Bulkeley, 2005). Partly as a result of globalisation, transnational actions are not rare but ubiquitous, and such actions in terms of global environment governance are becoming increasingly common (Rohrschneider and Dalton, 2008). The three most studied theoretical types of transnational networks in relation to global environmental governance are epistemic communities, transnational advocacy networks, and global civil society (Betsill and Bulkeley, 2004; 2006; Bulkeley, 2005). In epistemic community and transnational advocacy network approaches, national governments hold the central location of governance. The roles of sub-national governments are either ignored or implicitly subsumed within national governments, and their performances are measured in terms of the extent to which they shape, facilitate and change the behaviour of national governments. In the global civil society approach, the focus shifts to local level actors (mainly municipalities). Transnational collective actions by them indicate how a global challenge is being addressed by local actions. Given such a case, relevant international organisations and national governments should play the role of building up a well-functioning system that facilitates local actions (Sun et al., 2007).

Regarding the governance of climate change, the analysis of transnational networks is primarily concentrated on local governments in that they do not just respond to policy goals framed in national and international arenas, but also take initiatives in their own right (Sun et al., 2007). Betsill and Bulkeley (2006) list four reasons why municipalities are significant for CCM: (1) cities are sites of high energy consumption and waste production; (2) local governments engaging with issues of sustainable development have plenty of implications for CCM; (3) local governments can foster partnerships with relevant stakeholders, encourage public participation and lobby national governments; and (4) local governments have considerable experience in addressing environmental impacts, and innovative measures and strategies can serve as demonstration projects or the basis for experiments. Moreover, transnational municipal networks can, broadly speaking, provide member cities with three types of functions that are important for managing CCM, including information sharing, capacity building and implementation, and rules setting (Andonova et al., 2007). Although a transnational municipal network is dominated by member cities horizontally interacting with each other across the same level, it may not and should not focus on a single tier of governance, but rather involve levels of stakeholders from various fields, e.g. government, NGOs, private companies and importantly universities and research institution (Betsill and Bulkeley, 2006; Sun et al., 2007). This shows how international and local level could be interlinked within the governance network of global environmental challenges, and how a set of horizontal interactions can coalesce and turn into cooperative networks.

Worldwide, one of the largest transnational networks for mitigating climate change is the CCP Campaign, which was established in 1993 and now consists of more than 700 local governments accounting for approximately $15 \%$ of global anthropogenic GHG emissions (ICLEI, 2009). The CCP campaign assists cities in adopting policies and implementing quantifiable measures to reduce local GHG emissions, improve air quality, and enhance urban liveability and sustainability. To assist in achieving environmental goals, ICLEI helps member cities to undertake the five-milestone methodology and provides toolkits for monitoring and measuring GHG emissions. Through the CCP campaign, huge GHG reductions have been recorded, e.g. ICLEI helped US cities bring about 23 million tonnes of GHG reduction $\left(\mathrm{CO}_{2} \mathrm{e}\right)$ in 2005 (ICLEI, 2006), while CCP Australia reported 4.7 million tonnes $\mathrm{CO}_{2} \mathrm{e}$ reduction for 2007/08 (CCP Australia, 2008). In addition, a great amount of air pollutants and related energy costs have been reduced with the implementation of GHG reduction actions. With a decade of development of local actions for CCM, transnational municipal networks have become accepted as a legitimate area for research of CCM governance (Betsill and Bulkeley, 2007).

\section{Results and Discussion}

Climate change is currently the most important global environmental problems that require governance from international cooperation to local contributions to address its cross-scale and multi-level challenges. Two objects should be considered in the case of CCM, namely GHG emissions and the atmospheric sink, and the overall aim of managing CCM is to restrain the amount of GHG emissions within the absorption capacity of the atmospheric sink. However, plain top-down environmental governance is becoming less capable of addressing the cross-scale and multi-level challenges posed by global large-scale problems (Berkes, 2008; Carlsson and Sandström, 2008). Although there is no clear picture of what a robust governance system should comprise, it is certain that a highly functioning institution should be good for: (1) linking different types and levels of organisations, (2) exchanging resources, (3) allocating tasks, (4) reducing transaction costs, (5) sharing risks, and (6) enhancing conflict resolution mechanisms (Carlsson and Berkes, 2005; Carlsson and Sandström, 2008). Researchers are seeking possible solutions in many ways, and two most studied forms of institution are co-management and transnational networks.

These two forms of institution represent different ways in which the governance structure of large-scale environmental problems could be organised. Co-management aims to set up a flat cooperative network in which the power and responsibility are reconfigured among stakeholders vertically across multiple administrative levels. It has been verified by empirical studies and experiments on governing commons, especially CPRs (Carlsson and Sandström, 2008; Cash et al., 2006). However, successful co-management de facto often arises from adaptive, self-organising processes of learning by doing, rather than from a deliberative design process (Cash et al., 2006). Adger et al. (2005) show that such a process occurs because of the benefits stakeholders would like to gain by undertaking the action, or the costs they want to avoid by not undertaking it. In other words, successful comanagement is highly driven by practical economic benefits or incentives involving other critical resources. Co-management has 
not yet been widely analysed in the context of climate change. We therefore suggest that CDM projects be regarded as practical exercises in co-management and further tested in order to improve the theory and to galvanise future actions.

Transnational networks, by contrast, summarise the actions mainly conducted by a number of local actors operating or cooperating horizontally across national boundaries. By involving levels of stakeholders from various fields, a transnational network coalesces and develops into a cooperative network. The CCP campaign is one of the largest contemporary transnational networks in the domain of climate change. Worldwide, it has gained enormous interest on the local level and claimed substantial successes in terms of GHG reduction as well as other co-benefits. However, problems arise when scholars begin to examine transnational municipal networks in a more radical way. Betsill (2001) analyses three types of barriers that local governments have to overcome when the political will of CCM is translated into actions, namely (1) bureaucratic structure: there is often no institutional home for climate change policymaking; (2) administrative capacity: many cities lack the administrative capacity to develop local policies and programmes for CCM; and (3) budget constraints: many cities are not willing to invest much in CCM since doing so often requires significant up-front costs. Successful mitigations have been recorded when there are 'hooks' on which CCM can attach, i.e. issues that are relevant to CCM and important on the local agenda, such as air pollution and economic growth (Betsill, 2001). Thus, researchers suspect that the intention behind cities joining the CCP programme is to seek political and financial resources rather than to mitigate climate change (Betsill, 2007; Betsill and Bulkeley, 2004).

\subsection{Cooperative Networks}

To sum up, both branches are very likely to be effective forms of institution for addressing the cross-scale and multi-level challenges of large-scale environmental problems, although fraught with challenges and criticisms. It is thus useful to devise a general form of institution that might be able to address the cross-scale and multi-level challenges of CCM. Based on previous analysis, we found that both roads lead in the direction of building up cooperative networks where stakeholders can re-configure their power and responsibilities, share experiences and know-how, and provide resources and financial assistance for each other. In other words, cooperative networks, with emphasis either on the vertical interplay between administrative levels or horizontally organised interlinks, provide a general starting point for understanding the ways in which large-scale environmental challenges could be managed within and across multiple scales and levels (Betsill and Bulkeley, 2006).

While current cooperative networks indicate a possible way of handling the cross-scale and multi-level challenges of CCM, we then study the interactions between stakeholders in those two forms of cooperative networks and intend to identify useful rules to improve the current co-management and transnational networks. To be specific, an ICT is developed to theoretically illustrate those interactions respectively in the situation of CDM projects and CCP projects, where information and economic flows are used to represent various types of interactions between stakeholders (Table 1 and 2). Interactions based on non-market activities such as knowledge sharing, capacity building, education and training are referred to as 'information flow', while 'economic flow' represents types of market-based activities, e.g. investment, trading, employment and market services. Stakeholders considered in these two situations include an international organisation, two different countries ( $\mathrm{a}$ and $\mathrm{b}$ ), two local level stakeholders (decisionmaker or owner of a project), local citizen involved or affected by the project and other parties relating to the project, e.g. DoEs in the CDM situation. When there is a direct information or economic flow between two stakeholders, an 'I' or ' $E$ ' will be correspondingly recorded in the cell crossed by the two stakeholders.

As shown in Table 1 and 2, both types of institution consist of a large number of information and economic interactions between stakeholders. There are more economic interactions in CDM projects than in CCP projects and these economic interactions, as a hook-up between two countries, can often ensure concrete reductions and stimulate new opportunities for cooperation. By contrast, the information flows in CCP projects are both bigger in variety and higher in efficiency than those in CDM projects. For instance, the ICLEI annually reviews various mitigation measures adopted by member cities, regarding their costs and effectiveness, and this knowledge can largely help member cities to improve their own mitigation plan and attract more cities to join the network. Given the two types of cooperative networks are both as effective as announced, whether or not an institution is successful therefor does not depend on a single type of interactions or the number of interactions in general, while the quality of those interactions may be an important factor. In addition, local level stakeholders are found with the largest number of interactions in all levels of stakeholders. The reason lies in the fact that practical activities for GHG reduction remain the central focus of CCM management and that a working institution should be able to support these mitigation activities.

On the basis of those findings above, we further make suggestions as regards promoting cooperative networks as a working institution.

1) Cooperative networks must be able to involve relevant stakeholders and allow them to reconfigure their power and responsibility so as to facilitate CCM. Climate change represents an unprecedented large-scale environmental challenge that affects every corner on the earth, so every stakeholder, from international organisations to individuals and from industrialised countries to the developing world, should actively contribute to CCM. More importantly, stakeholders' roles in a cooperative network should be re-defined, rather than following top-down governance.

2) Effective interactions between stakeholders, either in the way of information sharing or economic flows, are important for a working cooperative network. In addition, co-management and transnational networks have often proven to be effective in managing large-scale problems when there are economic benefits or other incentives associated with types of interactions. Therefore, it is useful to create incentives between stakeholders, e.g. direct cost savings or information sharing about best practice, so that existing interactions could be strengthened and new interactions can be developed.

3) On the basis of above ICT analyses, there are two possible ways to improve the management of current CDM and CCP institution. For CDM projects, an annual review of registered projects, especially regarding the cost-effectiveness of projects of a certain category in a certain country, is valuable for both industrialised countries as purchasers and 
developing countries as producers of CERs. For CCP projects, it is very interesting that an economic cooperative mechanism, similar as transactions of CERs under the CDM, could be integrated into the current transnational network, where a stronger incentive of cooperation will promote and ensure more GHG reductions.

4) Cooperative networks can be developed and organised in many ways in practice and no one institution has proven capable of sustainable governance of climate change. Co-management has not been well discussed in the context of CCM, and many mitigation projects, such as CDM, can be used to verify its robustness. Transnational networks should be further developed in terms of both significance and effectiveness and a possible way towards this goal is to integrate economic incentives into the current institution. Since there is no conclusion regarding which institution is superior, it is necessary to encourage a diversity of forms of institution if cross-scale and multi-level challenges can be best addressed in one way or another.

\section{Conclusions}

This paper takes a commons perspective to study the large-scale environmental problem of climate change. In contrast to smallscale CPRs, climate change requires forms of governance that are able to address the scaling-up problem, while simultaneously dealing with reduction of GHG emissions and protecting the atmospheric sink. To this end, the paper analyses the two most studied forms of institution, co-management and transnational networks, which are very likely to be effective for addressing the cross-scale and multi-level challenges posed by management of CCM. These two forms of institution focus on vertically and horizontally organised cooperative networks, respectively. While cooperative networks have a general form of viability, this paper further adopts ICTs to illustrate those interactions between stakeholders in order to identify useful rules to improve the current forms of institution. On the basis of the ICT analysis, this paper suggests that (1) stakeholders should actively cooperate with each other and contribute to CCM; (2) effective interactions should be stimulated to promote the effectiveness of existing cooperative networks; (3) it is possible to improve the management of current CDM and CCP institution, for example, by integrating an annual review and an economic mechanism into the current networks, respectively; and (4) future studies should focus on both promoting current co-management and transnational networks and encouraging other possible forms of institution. 


\section{References}

Adger, W. N., Brown, K. \& Tompkins, E. L., 2005. The political economy of cross-scale networks in resource comanagement. Ecology and Society, 10 (2): 9.

Agrawal, A., 2002. Common Resources and Institutional Sustainability. In Ostrom, E., Dietz, T., Dolsak, N., Stern, P. C., Stonich, S. \& Weber, E. U. (Eds.) The Drama of the Commons. Washington, D. C., USA, National Academy Press.

Andonova, L., Betsill, M. M. \& Bulkeley, H., 2007. Transnational Climate Change Governance. In the 2007 Amsterdam Conference on the Human Dimensions of Global Environmental Change. May 24-26, 2007, Amsterdam, the Netherlands. Institute for Environmental Studies, Vrije Universiteit Amsterdam.

Barrett, S., 1990. The problem of Global Environmental Protection. Oxford Review of Economic Policy, 6 (1): 68-79.

Berkes, F., 2006. From Community-Based Resource Management to Complex Systems: The Scale Issue and Marine Commons. Ecology and Society, 11 (1): 45.

Berkes, F., 2008. Commons in a Multi-level world. International Journal of the Commons, 2 (1): 1-6.

Betsill, M. M., 2001. Mitigating Climate Change in US Cities: Opportunities and Obstacles. Local Environment, 6 (4): $393-$ 406.

Betsill, M. M., 2007. Regional Governance of Global Climate Change: The North American Commission for Environmental Cooperation. Global Environmental Politics, 7 (2): 11-27.

Betsill, M. M. \& Bulkeley, H., 2004. Transnational Networks and Global Environmental Governance: The Cities for Climate Protection Program. International Studies Quarterly, 48 (2): 471-493.

Betsill, M. M. \& Bulkeley, H., 2006. Cities and the Multilevel Governance of Global Climate Change. Global Governance, 12 (2): 141-159.

Betsill, M. M. \& Bulkeley, H., 2007. Looking Back and Thinking Ahead: A Decade of Cities and Climate Change Research. Local Environment, 12 (5): 447-456.

Bulkeley, H., 2005. Reconfiguring environmental governance: Towards a politics of scales and networks. Political Geography, 24 (8): 875-902.

Carlsson, L. \& Berkes, F., 2005. Co-management: concepts and methodological implications. Journal of Environmental Management, 75 (1): 65-76.

Carlsson, L. \& Sandström, A., 2008. Network Governance of the Commons. International Journal of the Commons, 2 (1): 3354.

Cash, D. W., Adger, W. N., Berkes, F., Garden, P., Lebel, L., Olsson, P., Pritchard, L. \& Young, O., 2006. Scale and cross-scale dynamics: governance and information in a multilevel world. Ecology and Society, 11 (2): 8.

CCP Australia, 2008. Local Government Action on Climate Change: CCP Australia Measures Evaluation Report 2008. ICLEI Oceania, Melbourne, Australia, http://www.iclei.org/index.php?id=ccp-reports, accessed on 2009-03-02.

Daly, H. E. \& Farley, J., 2003. Ecological Economics: Principles And Applications. Island Press, Washington, USA.

Dietz, T., Dolsak, N., Ostrom, E. \& Stern, P. C., 2002. The Drama of the Commons. In Ostrom, E., Dietz, T., Dolsak, N., Stern, P. C., Stonich, S. \& Weber, E. U. (Eds.) The Drama of the Commons. Washington, D. C., USA, National Academy Press.

Dietz, T., Ostrom, E. \& Stern, P. C., 2003. The Struggle to Govern the Commons. Science, 302 (5652): 1907-1912.

Feeny, D., Berkes, F., McCay, B. J. \& Acheson, J. M., 1990. The Tragedy of the Commons: Twenty-two years later. Human Ecology, 18 (1): 1-19.

Gustavsson, E., Elander, I. \& Lundmark, M., 2006. Multilevel Governance, Networking Cities and Climate Change Experiences from Two Swedish Cities. In The Sixth European Urban \& Regional Studies Conference. 21st - 24th September 2006, Roskilde, Denmark. the Wolfson Research Institute at the University of Durham Queen's Campus $\&$ the Department of Geography at Roskilde University.

Hardin, G., 1968. The Tragedy of the Commons. Science, 162 (3859): 1243-1248.

Houghton, J. T., 2001. Climate Change 2001: The Scientific Basis. Cambridge University Press Cambridge.

ICLEI, 2006. U.S. Cities for Climate Protection Progress Report. ICLEI - Local Governments for Sustainability, Oakland, USA, http://www.iclei.org/documents/USA/documents/CCP/ICLEI-CCP_US_Report-2006.pdf.

ICLEI, 2009. Cities for Climate Protection (CCP). http://www.iclei.org/index.php?id=global-contact-us, accessed on March $01,2009$.

IPCC, 2007. Climate Change 2007: Mitigation. Contribution of Working Group III to the Fourth Assessment Report of the Intergovernmental Panel on Climate Change. Cambridge University Press, Cambridge, United Kingdom and New York, NY, USA.

Kennedy, D., 2003. Sustainability and the Commons. Science, 302 (5652): 1861.

Milinski, M., Semmann, D., Krambeck, H.-J. \& Marotzke, J., 2006. Stabilizing the Earth's climate is not a losing game: Supporting evidence from public goods experiments. Proceedings of the National Academy of Sciences of the United States of America, 103 (11): 3994-3998.

Olsen, K. H. \& Fenhann, J., 2008. Sustainable development benefits of clean development mechanism projects A new methodology for sustainability assessment based on text analysis of the project design documents submitted for validation. Energy Policy, 36 (8): 2773-2784. 
Ostrom, E., 1990. Governing the Commons: the Evolution of Institution for Collective Action. Cambridge University Press, New York, US.

Ostrom, E., Burger, J., Field, C. B., Norgaard, R. B. \& Policansky, D., 1999. Revisiting the Commons: Local Lessons, Global Challenges. Science, 284 (5412): 278-282.

Ostrom, V. \& Ostrom, E., 1977. Public Goods and Public Choices. In Savas, E. S. (Ed.) Alternatives for Delivering Public Services - Toward improved performance. Boulder, U.S., Westview Press.

Paavola, J., 2008. Governing Atmospheric Sinks: the architecture of entitlements in the global commons. International Journal of the Commons, 2 (2): 313-336.

Rohrschneider, R. \& Dalton, R. J., 2008. A global network? Transnational cooperation among environmental groups. The Journal of Politics, 64 (02): 510-533.

Stern, P. C., Dietz, T. \& Ostrom, E., 2002. Research on the Commons: Lessons for Environmental Resource Managers. Environmental Practice, 4 (02): 61-64.

Sun, Q., Johansson, S., Wennersten, R. \& Brandt, N., 2007. System Analysis of Greenhouse Gas Abatement on the Municipal Level. In Proceedings of Research for Sustainable Development - The Social Challenge with Emphasis on Conditions for Change. September 6-7, 2007, Linköping University, Sweden.

Sutter, C. \& Parreño, J. C., 2007. Does the current Clean Development Mechanism (CDM) deliver its sustainable development claim? An analysis of officially registered CDM projects. Climatic Change, 84 (1): 75-90.

UNFCCC, 2009a. CDM Project Database. http://cdm.unfccc.int/Projects/projsearch.html, accessed on September $30^{\text {th }}, 2009$.

UNFCCC, 2009b. Graph on Project Cycle for CDM Project Activities. http://cdm.unfccc.int/CommonImages/ProjectCycleSlide, accessed on March 01, 2009.

van Laerhoven, F. \& Ostrom, E., 2007. Traditions and Trends in the Study of the Commons. International Journal of the Commons, 1 (1): 3-28.

World Bank, 1999. Report from the International CBNRM Workshop. Washington D.C., May 10-14, 1998. http://www.worldbank.org/wbi/conatrem/, accessed on March 1, 2009.

Young, O., 2006. Vertical interplay among scale-dependent environmental and resource regimes. Ecology and Society, 11 (1): 27. 


\section{Appendices}

Figure 1 Levels of stakeholders and so-management

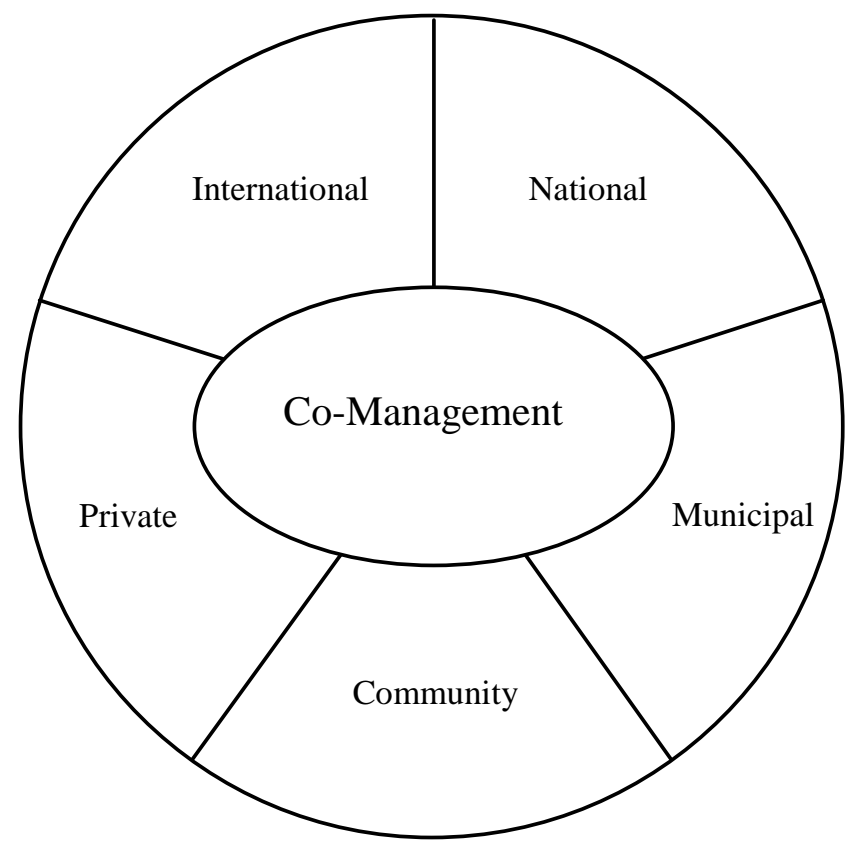

Adapted from World Bank, 1999. Report from the International CBNRM Workshop. Washington D.C. May 10-14, 1998. http://www.worldbank.org/wbi/conatrem/. 
Figure 2 Visualisation of clean development mechanism



Adapted from UNFCCC (2009b) Graph on Project Cycle for CDM Project Activities. http://cdm.unfccc.int/CommonImages/ProjectCycleSlide, accessed on March 01, 2009. 
Table 1 ICT: information and economic flows in CDM projects

\begin{tabular}{|c|c|c|c|c|c|c|c|c|}
\hline 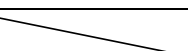 & International & National $_{\mathrm{a}}$ & Local $_{\mathrm{a}}$ & Citizen $_{a}$ & Other Parties & National $_{\mathrm{b}}$ & Local $_{b}$ & Citizen $_{\mathrm{b}}$ \\
\hline International & -- & I & I & I & I & I & I & \\
\hline National $_{\mathrm{a}}$ & I & -- & $\mathrm{I}, \mathrm{E}$ & & I & & & \\
\hline $\operatorname{Local}_{\mathrm{a}}$ & I & $\mathrm{I}, \mathrm{E}$ & -- & $\mathrm{I}, \mathrm{E}$ & $\mathrm{I}, \mathrm{E}$ & I & $\mathrm{I}, \mathrm{E}$ & \\
\hline Citizen $_{a}$ & I & & $\mathrm{I}, \mathrm{E}$ & -- & I & & & \\
\hline Other Parties & I & I & $\mathrm{I}, \mathrm{E}$ & I & -- & I & I & \\
\hline National $_{b}$ & I & & I & & I & -- & I & \\
\hline Local $_{\mathrm{b}}$ & I & & $\mathrm{I}, \mathrm{E}$ & & I & I & -- & \\
\hline Citizen $_{b}$ & & & & & & & & -- \\
\hline
\end{tabular}

- $\quad$ I: information flows, and E: economic flows

- ' $a$ ' refers to a developing country where a CDM projects is located and ' $b$ ' refers to an industrialised country that purchase the CERs from the CDM project.

- Indirect interactions are not considered in this table. 
Table 2 ICT: information and economic flows in CCP projects

\begin{tabular}{|c|c|c|c|c|c|c|c|c|}
\hline 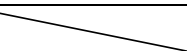 & International & National $_{\mathrm{a}}$ & $\overline{L o c a l}_{\mathrm{a}}$ & Citizen $_{a}$ & Other Parties & National $_{\mathrm{b}}$ & Local $_{b}$ & Citizen $_{b}$ \\
\hline International & -- & & I & I & & & I & $\mathrm{I}$ \\
\hline National $_{\mathrm{a}}$ & & -- & & & & & & \\
\hline $\operatorname{Local}_{\mathrm{a}}$ & I & & -- & $\mathrm{I}, \mathrm{E}$ & & & I & I \\
\hline Citizen $_{a}$ & I & & $\mathrm{I}, \mathrm{E}$ & -- & & & I & \\
\hline Other Parties & & & & & -- & & & \\
\hline National $_{b}$ & & & & & & -- & I & \\
\hline Local $_{\mathrm{b}}$ & I & & I & I & & I & -- & $\mathrm{I}, \mathrm{E}$ \\
\hline Citizen $_{b}$ & I & & I & & & & I, E & -- \\
\hline
\end{tabular}

- I: information flows, and E: economic flows

- ' 'a' and 'b' refers to two different countries, which both have a local level stakeholder participating in the CCP campaign.

- Indirect interactions are not considered in this table. 